\title{
Effectiveness of naked eye single tube osmotic fragility test for screening of $\beta$-thalassemia trait from north Maharashtra region, India
}

\author{
Mohammad Ismail ${ }^{1}$, Nisar G. Patel $^{2}$ \\ ${ }^{1}$ Department of Zoology, H.S.A.S. Arts and Science College, Deopur, Dhule-424002, Maharashtra, India \\ ${ }^{2}$ B.F. Patel Arts, Commerce and Science College, Pipalgaon kale Dist-Buldhana, Maharashtra, India
}

Received: 11March 2016

Revised: 15 March 2016

Accepted: 13 April 2016

*Correspondence:

Mr. Mohammad Ismail,

E-mail: ismailansari249@gmail.com

Copyright: ( ) the author(s), publisher and licensee Medip Academy. This is an open-access article distributed under the terms of the Creative Commons Attribution Non-Commercial License, which permits unrestricted non-commercial use, distribution, and reproduction in any medium, provided the original work is properly cited.

\begin{abstract}
Background: Thalassemia's are serious public health problem in all over the world. Different techniques are used for the diagnosis of different types of thalassemia's which are costly and time consuming. This study was aimed to determine the efficacy of naked eye single tube osmotic fragility test as a screening test for $\beta$-thalassemia trait and to standardize a saline concentration which could give best results with maximum sensitivity and specificity.

Methods: Three different buffered saline concentrations $(0.32 \%, 0.34 \%$ and $0.36 \%)$ were used. The test was applied to blood samples of 1702 family members from $130 \beta$-thalassemia major patients.

Results: The test results was compared and on the basis of our findings, recommend the use of $0.36 \%$ buffered saline. The test was positive in 589/629 subjects with $\beta$-thalassemia traits. The sensitivity of the test was $93.6 \%$ and specificity was $89.1 \%$. There were $10.9 \%$ false positive results in hematologically normal subjects. The test also gave positive results with $3 / 13 \alpha$-thalassemia and $20 / 24$ double heterozygous sickle/ $\beta$-thalassemia.

Conclusion: The test was proved to be useful in areas with high frequency of hemoglobinopathies and found simple, cheap and adaptable in under-resourced laboratories. However, it cannot replace red cell indices generated by automatic electronic cell counters.
\end{abstract}

Key words $\beta$-Thalassemia trait, NESTROFT, $\alpha$-Thalassemia, Buffered saline, Sensitivity, Specificity

\section{INTRODUCTION}

Hemoglobinopathies are serious public health problem in all over the world, of which the structural variants of hemoglobin such as sickle hemoglobin and disorders of globin chain synthesis the thalassemia's are the most common. ${ }^{1}$ It is estimated that, more than 300000 babies are born each year with either sickle cell anemia or one of its variants or different forms of thalassemia. ${ }^{2}$

Thalassemia's are inherited autosomal recessive disorders of hemoglobin synthesis caused by mutations on $\alpha$ - or $\beta$ globin genes resulting in decreased or no production of globin chains and hence decrease synthesis of hemoglobin and red cell survival. These hematologic disorders range from asymptomatic (heterozygotes/carrier state) to severe anemia (homozygotes/diseased) that can cause significant morbidity and mortality. Its prevalence is quite high in Southeast Asian countries and bear serious public health problem. ${ }^{3}$ In India each year more than 8000 to 10000 thalassemia major patients are born and overall prevalence of carriers are $3-4 \% .^{4-5}$

Many low or middle-income countries lacks well sophisticated laboratories for the control and management of these disorders and approximately $80 \%$ of the annual 
births of babies with these conditions occur in these countries. Preventing the birth of affected children is the best option in India, as most of the affected families are financially weak to manage the affected children. For this, the knowledge of the prevalence of $\beta$-thalassemia and other hemoglobinopathies in different regions and ethnic groups is essential.

The detection of different forms of thalassemia is more critical due to the possibility of interaction with other hemoglobinopathies which leads to serious clinical condition. In hypotonic solutions thalassemic red cells are resistant to lysis and this abnormal osmotic resistance were used in the diagnosis of thalassemia trait. The use of modified single-tube osmotic fragility test for thalassemia screening has been proposed for laboratories in developing countries. Earlier studies have recommended the use of $0.32 \%, 0.34 \%, 0.36 \%$ and $0.40 \%$ buffered saline solutions. ${ }^{6-9}$

However, $0.36 \%$ solution was comparatively more sensitive but less specific than $0.32 \%$ solution. ${ }^{7}$ Moreover, when the test is intended to screen $\alpha 0$ thalassemia $0.34 \%$ solution was recommended with detection of all $\beta$-thalassemia traits also being reported. ${ }^{9}$ Iron deficiency anemia and Hemoglobin $\mathrm{E}$ trait give significant proportion of false positive tests, but detection of $\mathrm{HbE}$ traits is a strength of the test rather than a weakness as the carrier frequency of $\mathrm{HbE}$ trait is quite high in Northeastern part of the country. ${ }^{7,9}$ Similarly, sickle cell traits also give positive test depending on the degree of the saline concentration. ${ }^{7,10}$

The present study was aimed to compare the sensitivity and specificity of $0.32 \%, 0.34 \%$, and $0.36 \%$ buffered saline for the diagnosis of $\beta$-thalassemia trait from north Maharashtra region. We also investigated the efficacy of the tests in the diagnosis of other hemoglobinopathies (sickle cell, $\alpha$-thalassemia, $\mathrm{HbE}$ and HbD Punjab), as the study area comes under sickle cell zone.

\section{METHODS}

The blood samples used in the present study were collected during the tenure of four years extended family study of 90 families consisted of $130 \beta$-thalassemia major patients. Venous blood samples of 1702 family members anti-coagulated with $\mathrm{K}_{2}$ EDTA underwent through different hematological test for identification of carriers of $\beta$-thalassemia.

Informed consent was obtained from all individual participants included in the study. The normal subjects identified during the family study and samples of $\alpha$ - and $\beta$-thalassemia, double heterozygous sickle/ $\beta$-thalassemia, $\mathrm{HbE}$ disease, traits and $\mathrm{HbE} / \beta$-thalassemia and $\mathrm{HbD}$ Punjab were enrolled in this study.

Initially osmotic fragility test with different saline concentrations $(0.32 \%, 0.34 \%$ and $0.36 \%)$ were performed with all samples without knowledge of the red-cell indices and/or HPLC. Analyses of hemoglobin were conducted by HPLC (Bio-Rad Variant II $\beta$ thalassemia short program; Bio-Rad Laboratories, Hercules, CA) at Shree Bhausaheb Hire Government Medical College, Dhule and cellulose acetate electrophoresis at alkaline $\mathrm{pH}$. Complete blood count was performed on each sample. Three different buffered saline solutions $(0.32 \%, 0.34 \%$ and $0.36 \%)$ were prepared according to the method described earlier. ${ }^{7}$

Solutions were prepared 3 months before the screening and were kept in sealed bottles at room temperature. The test was performed by taking $2 \mathrm{ml}$ of each of three concentrations of buffered saline solution in three separate test tubes $(10 \times 1 \mathrm{~cm}$ diameter $)$ and $2 \mathrm{ml}$ of distilled water in another tube, so that there was a set of four test tubes. $20 \mu \mathrm{l}$ of aliquot of whole blood was added to each of these four tubes. The tubes were shaken well and left undisturbed for half an hour at room temperature. After 30 minutes, each tube was mixed well by inverting many times and the tubes were held against a white paper on which a thin black line was already drawn for visual inspection.

The lines were clearly visible through the contents of the tube containing distilled water indicating complete lysis and if the lines were similarly visible through the contents of the tubes with buffered saline, then the test were read as negative. If the line was not visible the test was considered as positive. In case of turbidity caused the lines to be blurred, the test was considered as doubtful and this doubtful result was taken as being positive.

True positives (TP) are the positive test results given by thalassemia carriers and false negatives (FN) are the negative test results given by thalassemia carriers. Similarly, true negatives (TN) are the negative test results given by normal subjects and false positives (FP) are the positive test results given by the normal subjects.

The validity and efficiency of the test were calculated by following formulae.

Sensitivity: $\mathrm{TP} \div(\mathrm{TP}+\mathrm{FN}) \times 100$

Specificity: $\mathrm{TN} \div(\mathrm{TN}+\mathrm{FP}) \times 100$

Positive predictive value: $\mathrm{TP} \div(\mathrm{TP}+\mathrm{FP}) \times 100$

Negative predictive value: $\mathrm{TN} \div(\mathrm{TN}+\mathrm{FN}) \times 100$

Efficiency: $(\mathrm{TN}+\mathrm{TP}) \div(\mathrm{TP}+\mathrm{FP}+\mathrm{TN}+\mathrm{FN}) \times 100$

\section{RESULTS}

Table 1 summarizes the results of osmotic fragility screening in 1073 normal subjects. It was found that with $0.32 \%$ saline $90.5 \%$ of the normal subjects gave negative test results on the expense of $9.5 \%$ false positives, similarly $0.34 \%$ and $0.36 \%$ saline gives 87.2 and $89.1 \%$ with 12.8 and $10.9 \%$ false positives respectively. 
The osmotic fragility test results on $629 \beta$-thalassemia traits are summarized in Table 2 . The detection rate of heterozygous $\beta$-thalassemia (93.6\% suspicious and/or definitely positives) with $0.36 \%$ saline solution was found to be satisfactory with only $6.4 \%$ heterozygotes escaped from detection. While the test result with $0.32 \%$ and $0.34 \%$ saline solutions was found to be unsatisfactory with there being $22.1 \%$ and $11.3 \%$ false negatives respectively.

Table 1: Nestroft results in 1073 normal subjects using three strength of buffered saline.

\begin{tabular}{|llll|}
\hline $\begin{array}{l}\text { Strength of } \\
\text { buffered saline }\end{array}$ & Negative & Suspicious & $\begin{array}{l}\text { Pefinitely } \\
\text { positive }\end{array}$ \\
\hline $0.32 \%$ & $971(90.5 \%)$ & $31(2.9 \%)$ & $71(6.6 \%)$ \\
\hline $0.34 \%$ & $936(87.2 \%)$ & $48(4.5 \%)$ & $89(8.3 \%)$ \\
\hline $0.36 \%$ & $956(89.1 \%)$ & $41(3.8 \%)$ & $76(7.1 \%)$ \\
\hline
\end{tabular}

In addition to $\beta$-thalassemia trait, it is of interest to know whether $\alpha$-thalassemia trait, double heterozygous sickle/ $\beta$-thalassemia, $\mathrm{HbE}$ disease and traits, double heterozygous $\mathrm{HbE} / \beta$-thalassemia, $\mathrm{HbD}$ Punjab and $\mathrm{HbH}$ disease can be detected with this screening test. These patients were already diagnosed at some other centers and the samples of these patients were collected for evaluation.

Table 2: NESTROFT results in $629 \beta$-thalassemia traits using three strength of buffered saline.

\begin{tabular}{|c|c|c|c|}
\hline \multirow[b]{2}{*}{$\begin{array}{l}\text { Strength of } \\
\text { buffered saline }\end{array}$} & \multirow[b]{2}{*}{ Negative } & \multicolumn{2}{|l|}{ Positive } \\
\hline & & Suspicious & $\begin{array}{l}\text { Definitely } \\
\text { positive }\end{array}$ \\
\hline $0.32 \%$ & $139(22.1 \%)$ & $87(13.8 \%)$ & $403(64.1 \%)$ \\
\hline $0.34 \%$ & $71(11.3 \%)$ & $95(15.1 \%)$ & $463(73.6 \%)$ \\
\hline $0.36 \%$ & $40(6.4 \%)$ & $79(12.5 \%)$ & $510(81.1 \%)$ \\
\hline
\end{tabular}

Thirteen cases of genetically proven $\alpha$-thalassemia traits were available, but the results were quite unsatisfactory (Table 3). Three cases $(23.1 \%)$ of $\alpha$-thalassemia traits each were found to be suspicious or definitely positive with $0.32 \%$ and $0.36 \%$ buffered saline respectively and four cases $(30.8 \%)$ with $0.34 \%$ saline concentration.

Table 3: NESTROFT results in $13 \alpha$-thalassemia traits using three strength of buffered saline.

\begin{tabular}{|llll|}
$\begin{array}{l}\text { Strength of } \\
\text { buffered } \\
\text { saline }\end{array}$ & Negative & Positive & Suspicious \\
\hline $0.32 \%$ & $10(76.9 \%)$ & $\begin{array}{l}\text { Definitely } \\
\text { positive }\end{array}$ \\
\hline $0.34 \%$ & $9(69.2 \%)$ & $2(15.4 \%)$ & $2(15.4 \%)$ \\
\hline $0.36 \%$ & $10(76.9 \%)$ & $3(23.1 \%)$ & 0 \\
\hline
\end{tabular}

The detection rate for twenty-four double heterozygous sickle/ $\beta$-thalassemia was closing similar to that of $\beta$ thalassemia trait. All three buffered saline concentrations detected more than 19 out of 24 patients (Table 4 ). The percentage of suspicious and definitely positives were $83.3 \%, 79.1 \%$ and $83.3 \%$ with $0.32 \%, 0.34 \%$ and $0.36 \%$ saline strengths respectively.

Table 4: NESTROFT results in 24 double heterozygous sickle/ $\beta$-thalassemia using three strength of buffered saline.

\begin{tabular}{|llll|}
\hline $\begin{array}{l}\text { Strength of } \\
\text { buffered } \\
\text { saline }\end{array}$ & Negative & Positive & Suspicious \\
\hline $0.32 \%$ & $4(16.7 \%)$ & $\begin{array}{l}\text { Definitely } \\
\text { positive }\end{array}$ \\
\hline $0.34 \%$ & $5(20.8 \%)$ & $5(20.8 \%)$ & $15(62.5 \%)$ \\
\hline $0.36 \%$ & $4(16.7 \%)$ & $6(25 \%)$ & $14(58.3 \%)$ \\
\hline
\end{tabular}

There are fewer patient samples available with $\mathrm{HbE}$ disease, $\mathrm{HbE}$ trait, double heterozygous $\mathrm{HbE} / \beta$ thalassemia, $\mathrm{HbD}$ Punjab and $\mathrm{HbH}$ disease. Osmotic fragility test results for five cases of $\mathrm{HbE}$ disease with $0.32 \%, 0.34 \%$ and $0.36 \%$ saline solutions are $3(60 \%), 4$ $(80 \%)$ and $4(80 \%)$ suspicious and definitely positive respectively. The detection rate for $\mathrm{HbE}$ trait was unsatisfactory, $3 / 5,2 / 5$ and $2 / 5$ samples being missed with $0.32 \%, 0.34 \%$ and $0.36 \%$ saline solutions respectively.

Two patients with double heterozygous $\mathrm{HbE} / \beta$ thalassemia were detected with all saline solutions. Results with all saline solutions, hemoglobin D Punjab (HbD) gave $1 / 6,2 / 6$ and $2 / 6$ suspicious or positive respectively. A single sample from a patient with $\mathrm{HbH}$ disease gave a definitely positive result with $0.32 \%$ and $0.36 \%$ saline strengths and suspicious result with $0.34 \%$ saline solution.

Comparative analyses of sensitivity, specificity, positive and negative predictive values and efficiency of the test with various strength of saline concentration are shown in Table 5. Only samples of $\beta$-thalassemia trait and normal participants were chosen in this analysis.

Red cell indices (analyzed by Beckmen Coulter AcT 5 diff cell counter) of true positive and false negative cases (with $0.36 \%$ saline only) of $\beta$-thalassemia trait were compared by student's t-test (Table 6 ). The $P$ value $<0.05$ was considered as statistically significant.

The difference in hematological picture of the true positives and false negatives is statistically significant $(P<0.000)$. Of the 589 true positives $85(14.4 \%)$ have their RBC value less than $410^{12} / 1,250(42.4 \%)$ have their hemoglobin value between $7-10 \mathrm{~g} / \mathrm{dl}$. Out of 589 true positives $20(3.4 \%)$ have MCV greater than $80 \mathrm{fl}$. Almost all true positives have $\mathrm{MCH}$ value less than $27 \mathrm{pg}$.

Whereas, in false negative cases none of them have their $\mathrm{RBC}$ value less than $410^{12} / 1$. Out of 40 false negative cases nine $(22.5 \%)$ cases have their MCV value greater 
than $80 \mathrm{fl}$, only one case $(2.5 \%)$ has hemoglobin value between less than $10 \mathrm{~g} / \mathrm{dl}$, and three $(7.5 \%)$ cases have $\mathrm{MCH}$ value greater than $27 \mathrm{pg}$. True positive cases showed statistically significant decrease in all red cell indices but increase in mean $\mathrm{HbA}_{2}$ value compared to false negative cases.

Table 5: Sensitivity and specificity with various strengths of buffered saline in $\beta$-thalassemia traits.

\begin{tabular}{|llllll|}
\hline $\begin{array}{l}\text { Strength of } \\
\text { buffered saline }\end{array}$ & Sensitivity $\%$ & Specificity \% & $\begin{array}{l}\text { Positive predictive } \\
\text { value } \%\end{array}$ & $\begin{array}{l}\text { Negative predictive } \\
\text { value } \%\end{array}$ & Efficiency \% \\
\hline $0.32 \%$ & $77.9 \%$ & $90.5 \%$ & $83.8 \%$ & $86.6 \%$ & $85.6 \%$ \\
\hline $0.34 \%$ & $88.7 \%$ & $87.2 \%$ & $81.3 \%$ & $92.4 \%$ & $87.7 \%$ \\
\hline $0.36 \%$ & $93.6 \%$ & $89.1 \%$ & $84.4 \%$ & $95.7 \%$ & $90.8 \%$ \\
\hline
\end{tabular}

Table 6: Comparative analysis of red cell indices of true positive and false negative with $0.36 \%$ saline.

\begin{tabular}{|llllllll|}
\hline \multirow{2}{*}{ Parameters } & \multicolumn{2}{l}{ True positive $(\mathbf{n = 5 8 9})$} & \multicolumn{3}{ll}{ False negative $(\mathbf{n = 4 0 )}$} \\
& Range & Mean & SD & Range & Mean & SD & P value \\
\hline $\mathrm{RBC} 10^{12} / \mathrm{l}$ & $3.5-6.4$ & 4.7 & 0.6 & $4.2-6.3$ & 5.3 & 0.5 & $<0.000^{*}$ \\
\hline $\mathrm{Hb} \mathrm{g/dl}$ & $7.9-12.6$ & 9.9 & 0.9 & $9.8-14.5$ & 12.5 & 1.2 & $<0.000^{*}$ \\
\hline $\mathrm{Hct} \%$ & $24.5-39.7$ & 32.7 & 3.1 & $33.2-43.1$ & 38.4 & 2.8 & $<0.000^{*}$ \\
\hline $\mathrm{MCV} \mathrm{fl}$ & $54.1-91.3$ & 69.4 & 6.2 & $65.4-85.9$ & 73.3 & 5.3 & $<0.000^{*}$ \\
\hline $\mathrm{MCH} \mathrm{pg}$ & $15.9-26.9$ & 21.1 & 2.0 & $19.1-30.5$ & 23.7 & 2.4 & $<0.000^{*}$ \\
\hline $\mathrm{MCHC}$ g/dl & $22.9-40.6$ & 30.5 & 3.1 & $27.2-39.4$ & 32.6 & 2.8 & $<0.000^{*}$ \\
\hline $\mathrm{RDW} \%$ & $12.9-24.1$ & 17.0 & 2.2 & $11.2-21.2$ & 14.8 & 2.2 & $<0.000^{*}$ \\
\hline $\mathrm{HbA}_{2} \%$ & $3.5-9.9$ & 6.2 & 1.5 & $3.5-9.1$ & 5.2 & 1.4 & $<0.000^{*}$ \\
\hline
\end{tabular}

* Statistically significant.

\section{DISCUSSION}

Selection of proper screening tests and techniques together with consideration of cost of screening is very important in any population screening program, especially where the burden of other diseases is also quite high. In such population, carrier identification for $\beta$ thalassemia is extremely difficult. The main reason is the heterogeneity of $\beta$-thalassemia and absence of single test to elucidate all $\beta$-thalassemia variants. Various screening tests for carrier identification have been described, viz. complete blood count, estimation of $\mathrm{HbA}_{2}$ and $\mathrm{HbF}$. Instead of high accuracy these techniques are time consuming and expensive.

Osmotic fragility has been tested and evaluated over last many years on the other way is the best option for large population screening. Our results confirm previous findings suggesting that the NESTROFT is an inexpensive and satisfactory screening test for $\beta$ thalassemia.

In the present study we found a sensitivity of $93.6 \%$ with $0.36 \%$ saline, is quite comparable with sensitivities of $94.4 \%-95.5 \%$ reported earlier. ${ }^{10-13}$ Sensitivity of $0.32 \%$ saline solution indicated that it is insufficient for screening test and this is in agreement with the findings of Kattamis C, et al and Chow J, et al. ${ }^{7,13}$
Previous reports have shown considerable variation in specificities with $0.36 \%$ saline solution. In the present study we found a specificity of $89.1 \%$ which is quite comparable with the specificity $(91 \%)$ observed by Kattamis $\mathrm{C}$ et al whereas the specificities reported earlier varied from $64 \% 12$ to $95 \% .^{7,14}$ This variation in the specificity could be result from variable proportion of individuals with iron deficiency and/or a hemoglobinopathy investigated in different population. Here in the present study we did not include any patients with iron deficiency and in the assessment of sensitivity and specificity we did not include other hemoglobinopathies because it is a screening test rather than a definitive test and a positive test result with other hemoglobinopathy is an advantage rather than disadvantage.

The result of osmotic fragility in the detection of $\alpha$ thalassemia traits was unsatisfactory, but here we can't judge so, because the data is limited. Molecular analysis has revealed that out of thirteen cases four cases are $\alpha^{+}$thalassemia homozygotes and remaining are $\alpha^{+}$thalassemia heterozygotes. However, $0.34 \%$ saline was to be reported satisfactory. ${ }^{9}$

Hemoglobin E can also be detected through one-tube osmotic fragility test and this can be useful in population screening. ${ }^{7,9,15}$ However, it should be considered as a separate entity and an alternative strategy should be applied for the identification of this variant hemoglobin 
in population with high ethnic diversity and bothered with different hemoglobinopathies as in India. This is in agreement with those of Chow $\mathrm{J}$ et al. ${ }^{13}$

The one-tube osmotic fragility test could be considered as a screening test for double heterozygous sickle/ $\beta$ thalassemia especially in rural areas where the prevalence of sickle cell is quite high as in north Maharashtra region.16 Our result also suggests that some individuals with hemoglobin D Punjab could also be detected. Hematological data of these two cases of HbD Punjab positive with $0.36 \%$ saline was $\mathrm{MCV}<65.1$ and 68.2, $\mathrm{MCH}<20.8$ and 22.9 and hemoglobin analysis showed HbD was 28.7 and 31.1 .

The osmotic fragility test could lead to stigmatization and unnecessary referrals because of its high false positive (a disease mistakenly detected but in reality it is not) and false negative rates (a non-disease mistakenly detected but in reality it is) with $0.32 \%$ and $0.34 \%$ which could be characteristic of a test with low diagnostic accuracy. The possible reason could be the borderline $\mathrm{RBC}, \mathrm{Hb}, \mathrm{MCV}$ and MCH. Similarly with its high false positive rate (more numbers of normal samples diagnosed as having $\beta$ thalassemia) with all saline solutions could also reduce the efficacy of the test.

The probable reason for this high false positive rate would be erythrocytosis, highly marked leukocytosis and/or hyperlipidemia as reported earlier. ${ }^{17}$ Besides, when we keep the cost and convenience of the test in mind and comparing false negative and false positive rates, the osmotic fragility test found to be a best option for reducing the number of samples referred to high tech laboratories for further investigation. Moreover, instead of referring whole study samples directly to the laboratories for $\mathrm{CBC}$ and hemoglobin analysis, it is convenient and inexpensive for health care system to refer only NESTROFT positive samples. But here the question is what about false positive samples, these samples after further investigation by cell counter based parameters and hemoglobin analysis may be diagnosed as non-diseased.

The cost for the further investigation of false positive samples is definitely low as compared to whole study samples directly referred for $\mathrm{CBC}$ and hemoglobin analysis. But again one question is still remain here what about false negative samples. The possible answer would be the researcher should combine the osmotic fragility test with red blood cell morphology and red cell indices as it will reduce the false negative rate at some extent as shown earlier. ${ }^{18}$

\section{CONCLUSION}

Here we concluded that $0.36 \%$ saline would be the best option for the population screening in areas like north Maharashtra region where the prevalence of other hemoglobinopathies are also high.

\section{ACKNOWLEDGEMENTS}

Authors whould like to thank the Dean and faculty of Govonment Civil Hospital, Dhule, India for their assistance. Author's would also like to thank technical staff for their cooperation and University Grant Commission, New Delhi (Maulana Azad National Fellowship for minority students) for financial support.

Funding: No funding sources

Conflict of interest: None declared

Ethical approval: The study was approved by the Institutional Ethics Committee

\section{REFERENCES}

1. Weatherall DJ, Clegg JB. Genetic disorders of hemoglobin. Semin Hematol. 1999;36:24-37.

2. Modell B, Darlison M. Global epidemiology of hemoglobin disorders and derived service indicators. Bull WHO. 2008;86:480-7.

3. Weatherall DJ, Clegg JB. Inherited hemoglobin disorders: an increasing global health problem. Bull WHO. 2001;79:704-12.

4. Balgir RS. Genetic epidemiology of the three abnormal hemoglobins in India. J Assoc Physicians India. 1996;44:25-8.

5. Madan N, Sharma S, Sood SK, Colah R, Bhatia HM. Frequency of $\beta$-thalassemia trait and other hemoglobinopathies in northern and western India. Indian J Hum Genet. 2010;16:16-25.

6. Cao A, Galanello R, Furbetta M, Muroni PP, Garbato L, Rosatelli C, et al. Thalassaemia types and their incidence in Sardinia. J Med Genet. 1978;15:443-7.

7. Kattamis C, Efremov G, Pootrakul S. Effectiveness of one tube osmotic fragility screening in detecting $\beta$-thalassaemia trait. J Med Genet. 1981;18:266-70.

8. Thool AA, Walde MS, Shrikhande AV, Talib VH. A simple screening test for the detection of heterozygous beta thalassemia. Indian J Pathol Microbiol. 1998;41:423-6.

9. Panyasai S, Sringam P, Fucharoen G, Sanchaisuriya K, Fucharoen S. A simplified screening for $\alpha$ thalassemia 1 (SEA type) using a combination of a modified osmotic fragility test and a direct PCR on whole blood cell lysates. Acta Haematol. 2002;108:74-8.

10. Raghavan K, Lokeshwar M, Birewar N, Nigam V, Manglani MV, Raju NB. Evaluation of naked eye single tube osmotic fragility test in detecting $\beta$ thalassemia trait. Indian Pediatr. 1991;28:469-72.

11. Mehta BC, Gandhi S, Mehta JB, Kamath P. Naked eye single tube red cell osmotic fragility test for $\beta$ thalassemia: population survey. Indian J Hematol. 1988;6:187-90.

12. Manglani M, Lokeshwar MR, Vani VG, Bhatia N, Mhaskar V. NESTROFT-an effective screening test for $\beta$-thalassemia trait. Indian Pediatr. 1997;34:7027. 
13. Chow J, Phelan L, Bain BJ. Evaluation of single tube osmotic fragility as a screening test for thalassemia. Am J Hematol. 2005;79:198-201.

14. Maheshwari M, Arora S, Kabra M, Memon PS. Carrier screening and prenatal diagnosis of $\beta$ thalassemia. Indian Pediatr. 1999;36:1119-25.

15. Fucharoen G, Sanchaisuriya K, Sae-ung N, Dangwibul S, Fucharoen S. A simplified screening strategy for thalassemia and haemoglobin $\mathrm{E}$ in rural communities in Southeast Asia. Bull WHO 2004;82:364-72.

16. Kate SL. Health problem of tribal population groups from the state of Maharashtra. Indian J Med Sci. 2001;55:99-108.
17. Robert M, Schmidt MD, Sylvia MW. Standardization in detection of abnormal hemoglobins. Solubility tests for hemoglobin S. JAMA 1973;225:1225-30.

18. Silvestroni E, Bianco I. A highly cost effective method of mass screening for thalassemia. Br Med J. 1983;286:1007-9.

Cite this article as: Ismail M, Patel NG. Effectiveness of naked eye single tube osmotic fragility test for screening of $\beta$-thalassemia trait from north Maharashtra region, India. Int J Community Med Public Health 2016;3:1255-60. 